\title{
Modelling food system resilience: a scenario-based simulation modelling approach to explore future shocks and adaptations in the Australian food system
}

\author{
Seona Candy ${ }^{1}$ \& Che Biggs ${ }^{1}$ \& Kirsten Larsen ${ }^{1}$ \& Graham Turner $^{1}$ \\ 1 Victorian Eco-Innovation Lab, University of Melbourne, Melbourne, Australia \\ Corresponding author: Seona Candy candys@unimelb.edu.au
}

Abstract This paper outlines a process for exploring food system vulnerability and resilience using scenario modelling with the Australian Stocks and Flows Framework (ASFF). The capacity of ASFF to simulate how diverse shocks and stressors affect food system behaviour across multiple sectors-with diverse, interconnected and dynamic variables shaping system response-renders ASFF particularly suited for exploring complex issues of future food supply. We used ASFF to explore the significance of alternative agricultural policies for land use, crop production, livestock production, fisheries, food processing, transport, food waste and ultimately food supply. Policies in different scenarios varied with regard to the timetable for reducing greenhouse gas emissions, the degree of government participation or regulation in the food system and the scale of solutions (varying from centralized and global to decentralized and local). Results from the scenarios suggest that Australia does not have the ability to maintain a domestic surplus of foods required for a nutritious diet. In particular, the health of the current food system is highly vulnerable to constraints in oil supply, and increased food production threatens to precipitate a drastic decline in critical water supplies. We conclude by outlining a proposed method for using ASFF to delve deeper into the dynamics of the food system, probe the consequences of various adaptive responses to food production and supply challenges and devise potential indicators for food system resilience. Shocks and stressors to be added to the next phase of scenario

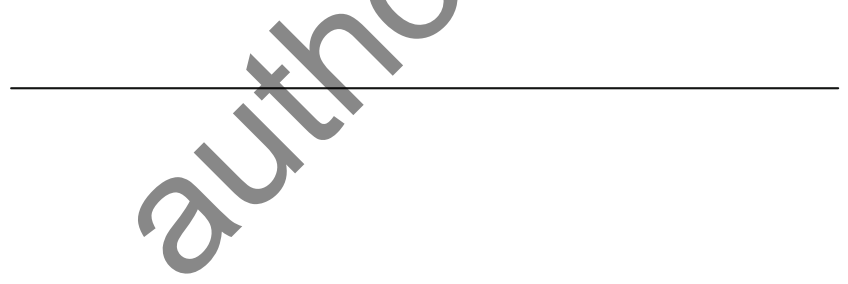

modelling include soil salinity, climate extremes and credit scarcity. The ASFF methodology should be applicable to other parts of the world, although appropriate recalibration and adjustment of model assumptions would be required to reflect regional differences.

\section{Introduction}

According to different reports, the state of Australian food and agriculture sectors is either the 'food bowl' for Asia (Australian Government 2014) or a 'dust bowl' waiting to happen (Garnaut 2008). Despite decades of poor land management, frequent droughts and major floods, Australia is a significant net exporter of food. It employs state-of-the-art techniques to allocate scarce water resources, manage complex salinity problems and coordinate highly efficient national supply chain networks that rarely fail. In many respects, the Australian food system is highly functional and appears resilient (PMSEIC 2010). Conversely, shifts in climate conditions, soil degradation, limited global phosphorus stocks and declines in Australia's manufacturing sector and its farming population (among many other factors) suggest the food system is vulnerable and the outlook is not rosy (Farmar-Bowers et al. 2013). This reliance on finite resource inputs has potential threats to both production and distribution, as do extreme weather events. Both these perspectives may be valid. But how do we know that vulnerabilities are not precursors to systemic failure and that the Australian food system will be resilient over the long term? Can Australia remain a regional food bowl, or is this a dangerous myth? What would an Australian food system look like if it were to survive and thrive in a world of climate change and oil scarcity? 
This paper outlines a project and method of using the Australian Stocks and Flows Framework (ASFF) to explore these types of issues by modelling the dynamics underpinning the healthy function and resilience of Australia's food system. It aims to show how system dynamic modelling can help our understanding of what factors underpin the resilience of the Australian food system and where leverage points exist to reduce vulnerability. We explain why scenario modelling is a suitable (and increasingly used) method for exploring food systems and food security and how scenario modelling using ASFF is being used to explore food availability and stability in Australia, a country similar to other food-exporting nations such as the USA and Canada in terms of its economic wealth and industrialised food and agricultural systems. We then describe how this approach will be extended to explore food system resilience in the Australian Food Supply Scenarios Project. As outlined in more detail below, ASFF enables us to find and analyse the 'holes in the arguments' often disguised by complexity and the number of factors that need to be considered. This approach relies on a combination of qualitative and quantitative components. The qualitative analysis uses scenarios incorporating a wide range of factors and relationships from economic, social and cultural domains. The quantitative analysis concerns the physical implications of these scenarios and describes their impacts on land, water, energy, etc. While acknowledging that production is only one part of the food system, it tends to become the focus of the quantitative analysis simply due to the relative availability of data and the maturity of these calculators in the model

The paper will introduce how a dynamic understanding of the food system can be obtained via scenario modelling and how ASFF calculators can be configured to provide these models. It demonstrates how ASFF can be used to explore the key stocks and flows of the Australian food system and how it could be extended to testing and understanding resilience in food systems.

\section{Building a dynamic understanding of the food system}

Our position is that a well-functioning food system '... exists when all people, at all times, have physical, social and economic access to sufficient, safe and nutritious food that meets their dietary needs and food preferences for an active and healthy life' (World Food Summit, 1996). This is a standard definition of food security and describes a desired state.

When we refer to food system resilience, we mean the system's capacity to maintain this desired state in the face of disturbances. This is in line with the definition of resilience as the capacity to retain essential structures and functions and identify despite disturbances (Gunderson 2000).

While food security is clearly dependant on food system resilience, apparent food security (such as that which is the case in Australia at present) is not an indicator of food system resilience. According to the FAO, two key aspects of food security are food availability - relating to the quantities of safe, nutritious food available_and stability-relating to the availability of that food at all times (FAO 2006, p. 1). Having sufficient food available consistently is an essential part of being food secure. But this condition is the outcome of multiple interactions and processes. As researchers point out, the key factors underpinning food security (access, affordability and use) are poor indicators of food system vulnerability (Ericksen 2008; Ericksen et al. 2009). In contrast to focusing on desired outputs, they call for a systemic approach to understanding of food system health and a focus on functions and the relationships between functions that underpin food availability.

Levels of production do not reflect a stable supply of nutritious food. Food supply chains are complex systems involving production, distribution and storage, often designed for efficiency rather than resilience (Keating 2013). This is evident in almost all aspects of the Australian food system. Agricultural production is dominated by large-scale, singlecrop or minimal rotation farming dependent on external chemical inputs, irrigation and mechanisation (Henzell 2007, p. 39). Distribution systems use mostly road freight with increasingly longer supply chains, based on 'just in time' practices (Bartos 2012). Spurred on by concern for market efficiency and as a matter of international trade policy (OECD-FAO, 2008), Australia also does not currently hold any food reserves for use in the event of a major disruption to the food supply (Keating 2013). The food system is therefore vulnerable to short-term shocks such as oil and fertiliser price spikes and extreme weather events that disrupt food access and allocation.

Practices that increase production at the expense of essential eco-system services can also result in (and exacerbate) more gradual stressors such as land degradation and water scarcity. These have implications for long-term productivity and future food production (Dalal and Mayer 1986; NLWRA 2001). Rather than causing sudden events or shocks, these factors result in a slow decline in both the health and the adaptive capacity of the food system or sub-systems within it.

\section{Scenario modelling to explore food systems security}

The food system is an irreducibly complex socio-ecological system. Scenario modelling is a useful tool for exploring such systems, because it allows analysts to investigate multiple trajectories of change without allocating probability. In so doing, we can identify decisions that are robust for multiple futures and potentially find variables that contribute to a more resilient food system under different scenario conditions.

Increasingly, assessments of the global food supply combine 'what-if' scenarios that explore multiple possible futures 


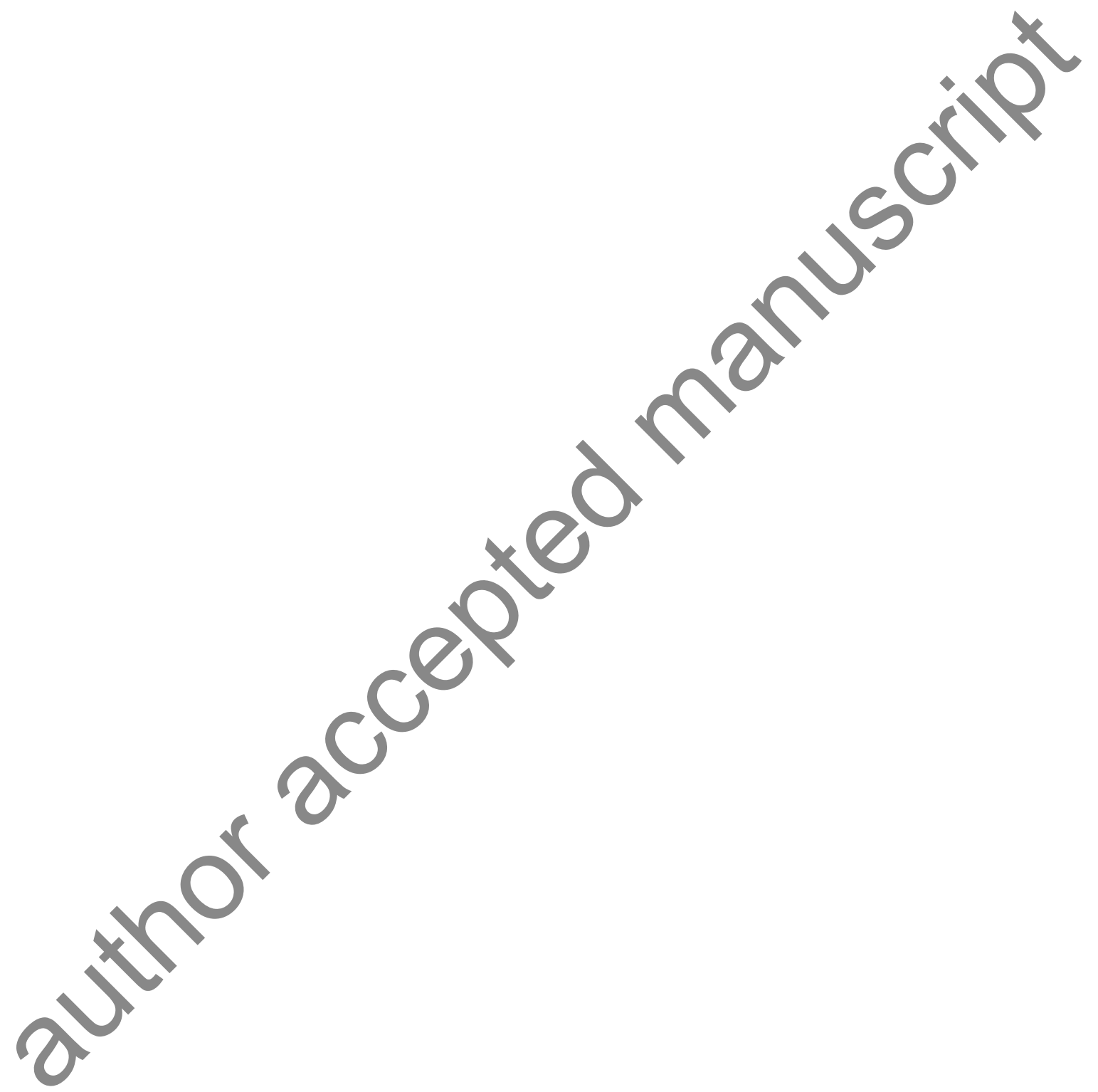


for food security with quantitative modelling (Erb et al. 2009; Reilly and Willenbockel 2010). Qualitative 'what-if' or 'exploratory' scenarios use plausible, internally consistent stories of alternate futures-each involving different drivers of change and exploring possible consequences from the interaction between these drivers. Scenarios then form the basis to explore possible future developments and different policy or cultural responses to complex problems. In this process, developing and testing scenarios allow influential factors to be identified and give clues as to what points of leverage may be used to influence drivers of change (Snoek 2003).

Scenario modelling is a combination of scenario analysis and system modelling (Reilly and Willenbockel 2010). Qualitative scenarios are first developed and are then translated into quantitative scenarios to enable computational analysis of key settings. The quantities, rates, proportions and even end results can be set empirically to allow exploration of critical relationships. In practice, few scenario parameters are 'locked' allowing the analyst to assess adjust variables and assess their consequences. This process helps to reveal complex relationships, unexpected system behaviours and trace internal system dependencies that are often ignored or poorly understood.

When analysing the sustainability and resilience of the food system, quantitative models that represent it as a subsystem or part of a larger physical economy or system are considered to be the most suitable. This is known as a system dynamic approach, which recognises that the structure of any system, and the interdependent and sometimes time delayed relationships between its components, is often just as important in determining its behaviour as the individual components themselves (Forrester 1971). This is because the food system relies on other systems to operate, such as theenergy and materials sectors; competes with others for resources such as labour, fuel and water and is also susceptible to impacts caused by their operation, such as emissions-driven climate change that threatens food production in the future.

Recent research by Larsen etal. (2011) developed a scenario modelling process that made new use of an existing physical model of the Australian economy - the Australian Stocks and Flows Framework model (ASFF) to track the complex interaction of land and resource systems as they affect the availability of food in the state of Victoria. It is important to note that the ASFF model differs slightly from traditional system dynamic models in its treatment of feedbacks because they are nothard-wired in the framework, according to the 'Design Approach' (Gault et al. 1987). Aside from minor feedbacks incorporated at the level of individual stocks and the potential to use feedback explicitly at the module or 'calculator' level, feedback between modules is restricted to that provided by users responding to tensions displayed in ASFF, to complementary code written specifically for the feedback task, or coupling with other models or analysis. This approach to high-level feedbacks emphasises the importance of human decisions and behaviour (individual, social or economic) in response to the bio-physical system (Turner et al. 2011).

\section{The Australian Stocks and Flows Framework for food systems analysis}

\section{Introduction to the Australian Stocks And Flows Framework}

The Australian Stocks and Flows Framework (ASFF) was developed in the mid-1990s by the Commonwealth Scientific and Industrial Research Organisation (CSIRO) as a scenario-modelling platform. ASFF was designed as a scientific and policy tool to study the interplay between factors such as population, technology, lifestyles and the environment (Poldy and Conroy 2000).

ASFF acts as a "calculator' for the physical processes that underlie economic activity, an accounting system that tracks land, water, energy, employment and materials required for economic activity to actually occur (Fig. 1). It takes assumptions about economic activity and development and reveals whether they meet fundamental thermodynamic constraints, like the conservation of mass and energy. It covers all the physical elements of each sector of the Australian economy that are significant from a thermodynamic perspective, including some service aspects. Natural resources (land, water, air, biomass and mineral resources) are represented explicitly. This allows tensions in resource use to be identified and informed trade-offs to be made (Turner et al. 2011). Imports are first calculated as a specified fraction of domestic consumption requirement, but may actually be increased to meet any remaining consumption requirement if domestic production is insufficient. Exports occur when there is surplus domestic production, after accounting for consumption and imports.

For each simulation, the model is first run over a historical period from 1946, after which future scenarios are then calculated to 2100. To provide an accurate 'launch pad' for the scenarios, the historical period is calibrated to ensure that the model outputs are entirely consistent with observed data from reputable sources such as the Australian Bureau of Statistics (ABS). Calibration involves assembly and formatting of all relevant data sets, estimation of missing data, correction of erroneous data and estimation of parameters and variables that do not have any observed data (see e.g. Baynes et al. 2010). The estimation of values for some variables may be comparatively free or in other cases completely constrained depending on the relationships described in the model and the observed data that is available.

ASFF was first commissioned by the Immigration Department to report on environmental implications of alternative population trajectories and generated considerable research and media attention. 


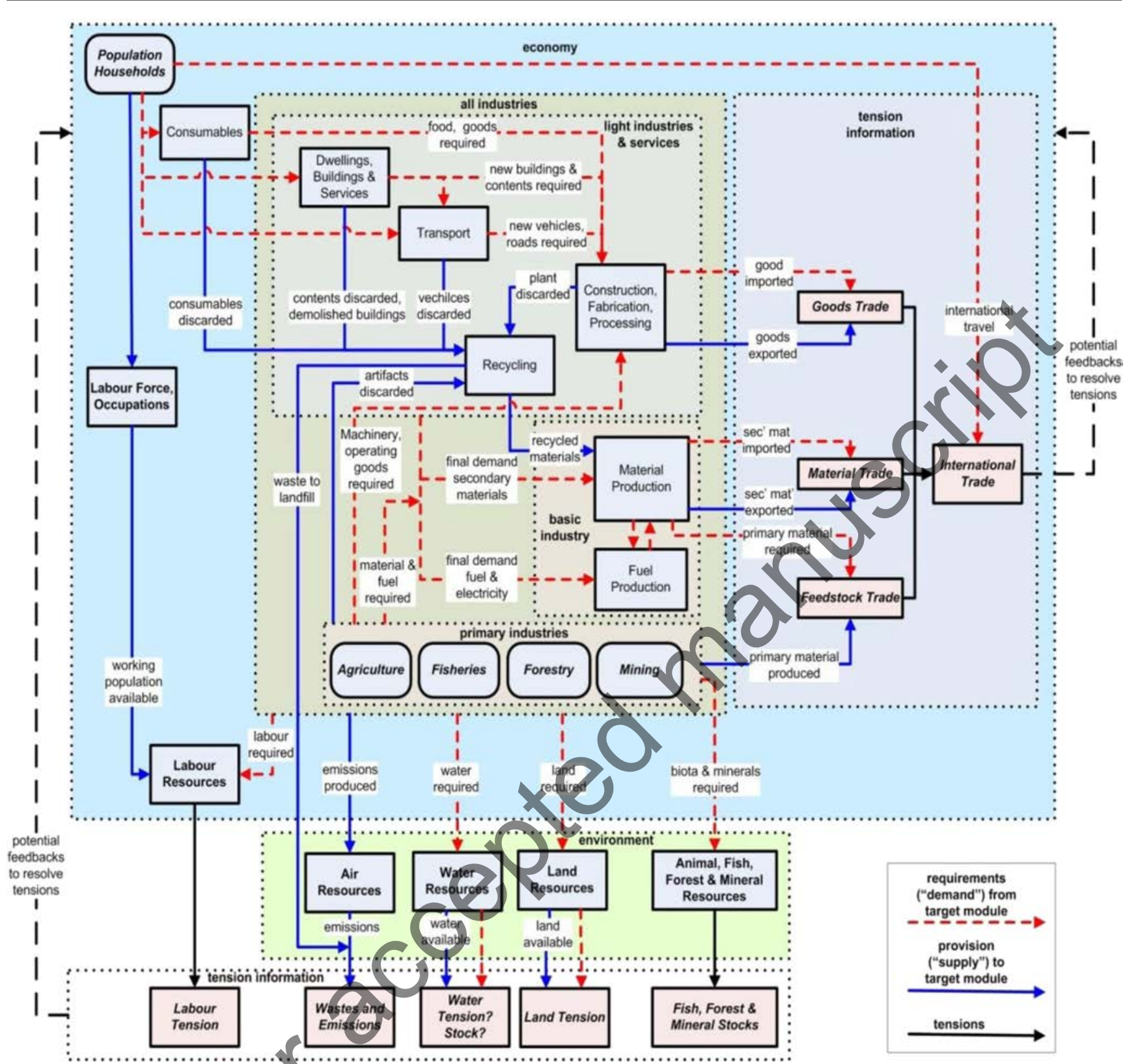

Fig. 1 Major components and information flows in the ASFF. Components, shown as boxes, and information flows (arrows) between components of the ASFF. Requirements from one component of another are shown as dashed red lines. Flows produced by one component for another are show as solid blue lines. Two major components, demography and primary industries, are entirely exogenous. Components to the right and bottom of the diagram only receive information flows and present any tensions (mismatches) between requirements and provisions associated with international trade, natural resources, waste/emissions and labour (source: Turner et al. 2011)
Since then, the ASFF and related models have been employed by many clients on a wide variety of sustainability studies, including population and immigration (Sobels et al. 2010), green collar employment (Hatfield-Dodds et al. 2008), renewable electricity (Turner et al. 2013), water-energy and urban form (Kenway et al. 2014), cropping (Dunlop et al. 2004), fisheries (Lowe et al. 2003), transport and climate change (Jones and Turner 2005). It has also been used to explore future food supply scenarios as explained in the following section.

\section{ASFF and the food system}

Food availability and stability of supply are dependent on a number of factors across different temporal and spatial scales. By focusing on short-term or local food supply dynamics and critical outputs such as volume of production, analysts can miss underlying dynamics that influence food systems over the long term (Ericksen et al. 2010). For example, while intensive agricultural practices of the Green Revolution resulted in a rapid and prolonged increase in agricultural production, in 
many places, they have caused gradual but severe degradation of soil and water resources (FAO 2011; Singh 2000). This section outlines the relevant calculators in ASFF that relate to the food system and shows how ASFF can be used to explore food supply scenarios.

Exploration of food supply scenarios in ASFF uses the models existing crops and land, animals, fisheries and food processing calculators (Turner et al. 2011). These include aspects of primary food production (including the division of land use, land state, crop and livestock production and fish farming), as well as additional parameters relating to food processing, food waste throughout the food system and food consumption patterns. These calculators are outlined in more detail below. Additional adjustments to account for changing food production practices are ongoing in the broader Australian Food Supply Scenarios Project.

Land use and land state

Currently, land stocks in ASFF are divided into urban, agricultural and forestry classes for spatially defined statistical divisions (SD). In the crops and land calculator, land use is specified according to the type of activity and intensity according to broad-acre agricultural methods. Figure 2 shows how land use and land state is represented in ASFF and incorporated into the food system. The boxes bordered with the blue dotted line show the interaction between land state and crops and or animals via 'land activity', elaborated further in Fig. 3.

For the agricultural land stock, land state is determined based on land vintage (time under cultivation) and history of land activity (crop + intensity). Change in land state over time is represented by landscape function measures (acidity, dryland salinity, irrigation salinity and soil structure). All land activity categories except 'fallow' and 'idle' result in land degradation. Landscape function scores are used to calculate yield factors, which are combined to produce a single "landscape function yield factor' for each vintage. This yield factor defines yield decline rates due to loss in landscape function. Landscape function yield factors are then combined with yield factors for other components of the agricultural system (genetics, irrigation, fertiliser) and areas under different land uses to calculate total crop and pasture production in each SD.

\section{Crop production}

In the 'crops and land' calculator, there is a procedure that determines the agricultural land activity for the proportion of agricultural land in each SD. It incorporates different levels of intensity based on broad-acre (extensive) farming techniques (Fig. 3).

The agricultural land activity is determined based on the land activity share (the proportion of each SD's land under each activity), activity per period (the frequency per 5 years of the activity), crop type and level of intensity. The available crop types and levels of intensity are listed in Fig. 3. Subsequent crop yields are determined based on land activity and other factors such as weather and genetic factors, trophic response, fertiliser response and irrigation factors (where applicable).

Based on the land activity, the agricultural operations calculator then determines agricultural operations required and the subsequent energy, materials, water, fertiliser and labour required on a per hectare basis.

\section{Livestock production}

Livestock production is incorporated into the ASFF with the 'animals' calculator. Similar to the 'crop and land' calculator, some variation of intensity is possible but is based on broadacre (extensive) farming methods and mainly incorporates feeding intensity. The proportion of each livestock type and the intensity are specified via exogenous inputs, from which the livestock products are calculated. The livestock types available include meat cattle, producing and non-producing dairy cattle, pigs, sheep, egg poultry and meat poultry. The livestock produets are listed in Fig. 3.

The 'animals' calculator deals primarily with animal products and feed required. The associated energy, water, materials and labour required are calculated in the 'agricultural operations' calculator. Some additional resources are also accounted for in the production of crops for animal feed. Manure production is quantified, and it is also possible to specify the proportion of diet provided from grazing or from feed grown on separate land.

\section{Fisheries}

The 'fisheries' calculator in ASFF covers all fishing activity in ocean and fresh water areas (wild fishing) and in fish farms. It keeps track of primary fish production through to ultimate human consumption and utilisation.

This calculator deals primarily with the treatment of 48 fish stocks ('fisheries') modelled in the ASFF and the harvesting of fish from those stocks. The calculator determines the actual catches from these fisheries based on a requested catch, the effect of catches on the stock levels and the stock levels throughout the simulation. A simple logistics population model for each fish unit is used to determine how quickly fish stocks can be replenished in each fishery, including the effects of recreational fishing and predators, such as seals. The calculator also determines the effort (in boat days) required to provide the actual catch, as well as evolving the boat stock needed to meet this effort and the material, labour and energy inputs for the fishing activity. These inputs are also calculated for the fish farming activity in Australia, though the levels of 


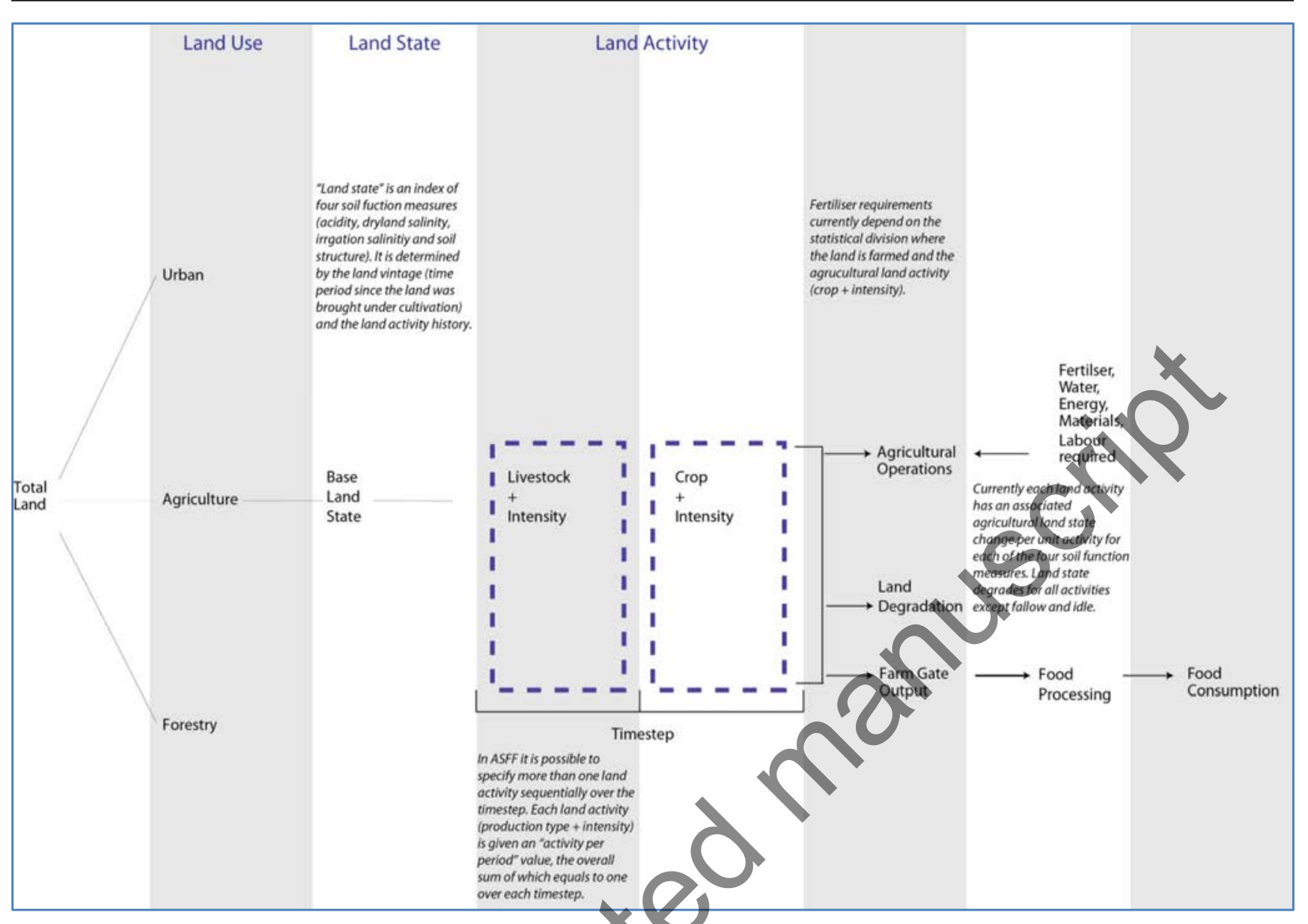

Fig. 2 Land use and land state in ASFF with detailed sections relating to the food system

production of fish from fish farming is not modelled but specified exogenously.

Food processing, transport and food waste

The concept of waste in the food system is currently not specifically addressed in the ASFF and the modelling of food processing is very basic. Net yields at the farm gate are based on statistical data, so yield losses due to pests, disease and natural destruction are already included and wastage is not calculated explicitly. Animal manure waste can be accounted for and quantified.

Per capita food consumption is treated in 'farm gate' terms, that is, food commodities are simply a subset of the primary material products of agriculture and fishing, with no allowance made for processing and wastage. To quantify the effects of reducing waste on resources used and emissions produced, existing inputs and outputs can be strategically increased or decreased in relation to each other. In past research (Larsen et al. 2011), impacts of different levels of waste were modelled by simply increasing the per capita food consumption by different percentages.
Further work is currently being done on the model to develop the food processing and transport sections though to represent the 'farm-gate to checkout' section of the food system, to accurately compare the impacts of different waste reduction methods. Different representative diet profiles are also being determined and translated into ASFF production amounts to explore the impact of altering consumption patterns.

\section{Example of food system scenario modelling with ASFF-Victorian Food Supply Scenarios Project}

The Victorian Food Supply Scenarios Project was a 12-month research project funded by the Victorian Health Promotion Foundation (VicHealth) which developed and demonstrated a new process using scenario modelling to link land and resource use with availability of a nutritionally adequate food supply for the population of the state of Victoria, Australia. The nutritionally adequate food supply was calculated by estimating the amount and variety of foods required to meet the recommendations of nutrition reference standards (according to Commonwealth Department of Health and Ageing 1998), 


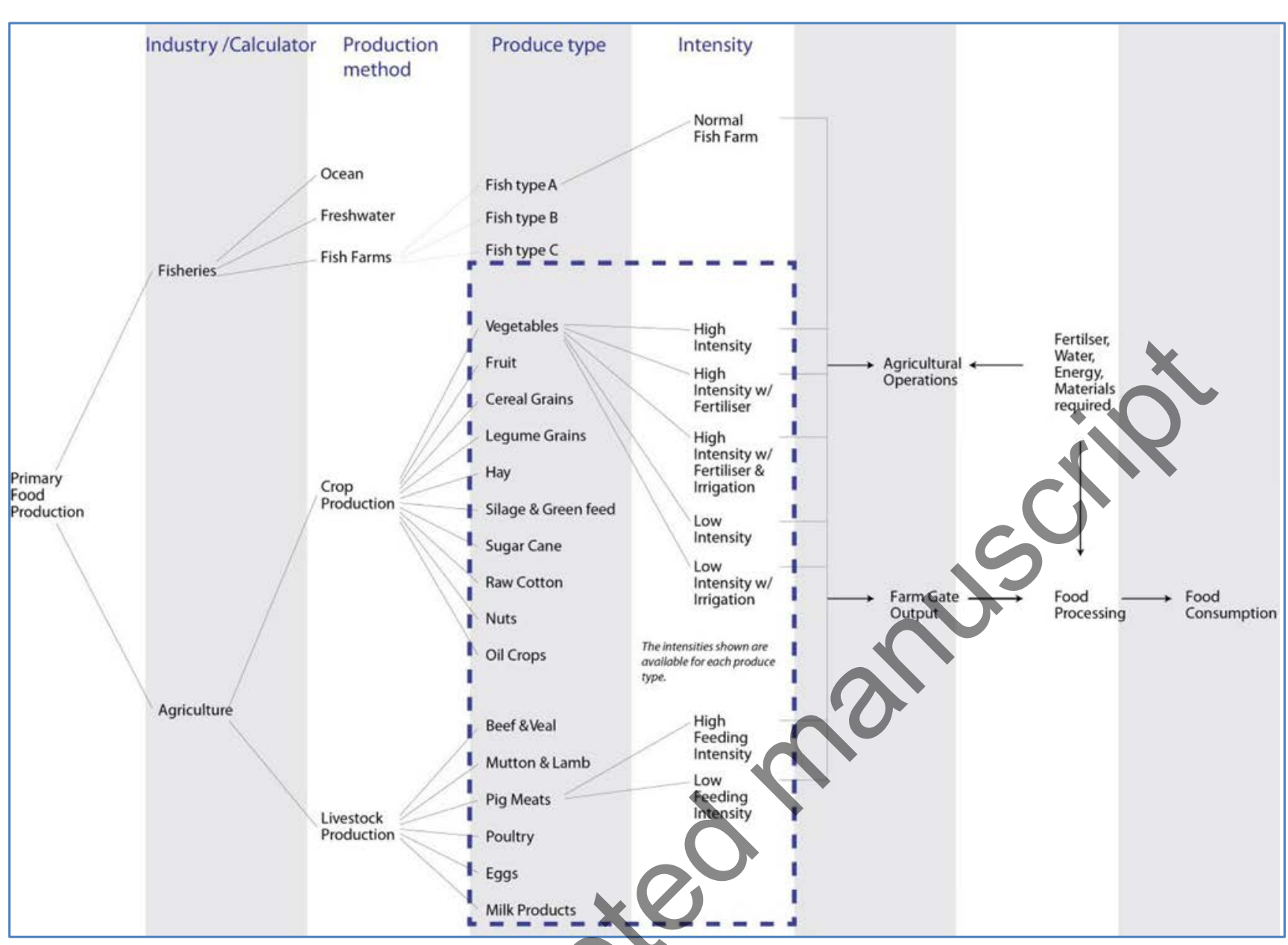

Fig. 3 Major components of food production in ASFF

selecting foods to represent each food group, selecting the population categories for which the nutrition implications would be assessed, determining the number of recommended serves for each food group, and then estimating the amounts of foodstuffs required to meet the nutrition reference standards for the population. ASFF was then used to track the complex interaction of land and resource systems as they affect the availability of food (Larsen et al. 2011).

\section{Qualitative scenario development}

A participatory scenario development process was held in 2009. From this process, there were three significant dynamics of change identified that were considered most likely to shape the Victorian food system. These were the following:

\& Speed and effectiveness of greenhouse gas emissions reductions;

\& Extent to which governments intervene to manage food and energy security concerns; and

\& Scale of solutions: global, national or local/regional.
Exploring different possible responses and configurations of these key dynamics resulted in the qualitative scenarios summarised in Fig. 4.

It is important to note that the 'time to take control' scenario is referred to in the following sections as 'control'. It should not be confused with the term 'control' which is commonly used in experimental analysis as a reference to baseline results.

\section{Quantitative settings}

The quantitative settings for each scenario included common settings across all scenarios, such as population growth rates, as well as variable settings that make each scenario operate differently from the background scenario and each other. These variable settings are shown in Table 1.

The greenhouse emission targets in Table 1 represent the level of ambition suggested by the qualitative scenarios and were used to guide initial estimates of what other settings should be.

The amount of food 'required' in the scenarios is set as the amount needed to meet nutritional and energy 

(source: Larsen et al. 2011). The scenarios are framed by these three divergent axes-each scenario is defined by three 'ends' closest to the box
Fig. 4 Scenario logic diagram

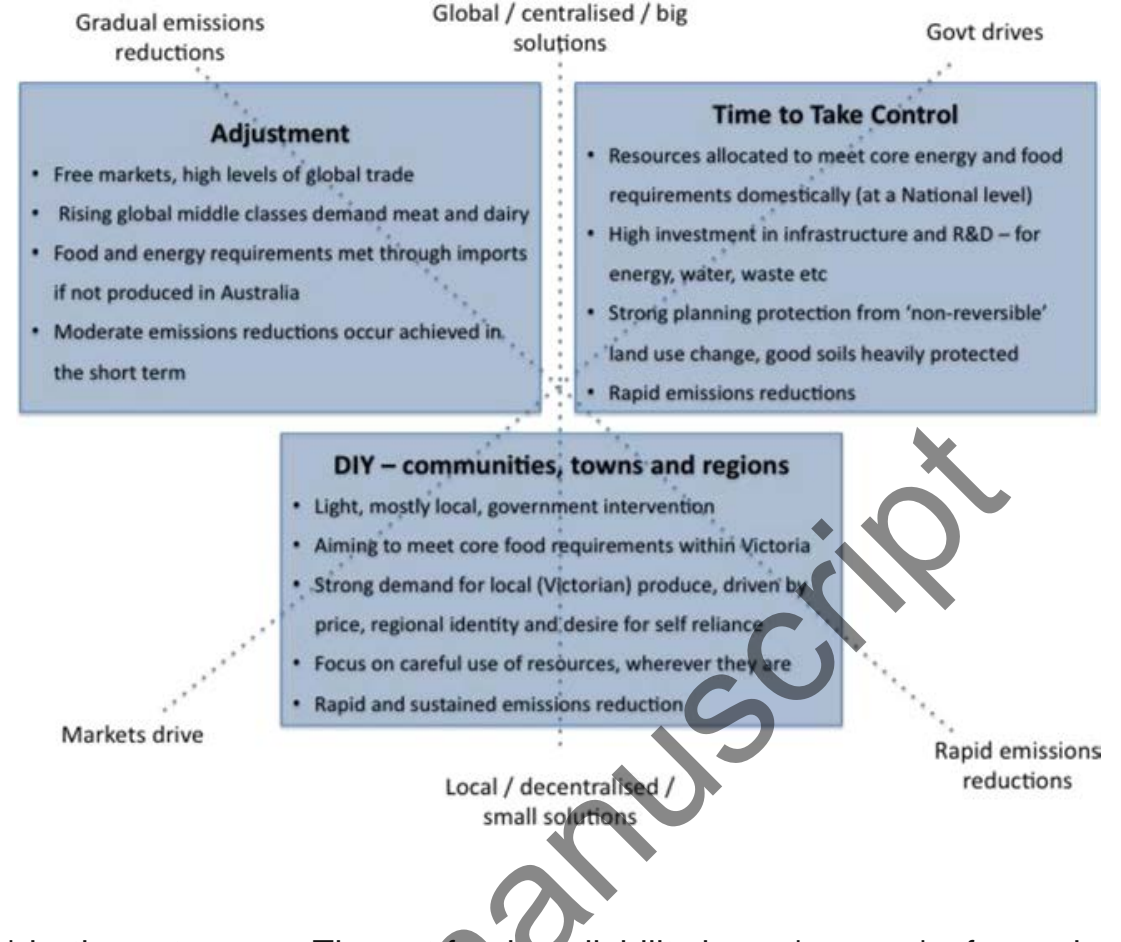

The net food availability in each scenario for major food groups is shown in Table 2. It can be seen that a domestic surplus of foods that are required for a nutritious diet for the population has not been achieved in any of the three scenarios.

Despite significant uncertainties in the data and analysis, he project strongly suggested a more sophisticated and strategic approach to resource allocation required if food and energy security, greenhouse emissions reductions, sustainable resource use, a healthy environment and a viable economy are to be achieved simultaneously.

That pilot project revealed significant tensions between assumptions about policy and economic pathways for Australia and the ability to provide a nutritious diet to the population and the environmental/resource implications of doing so. Examples of the environmental and resource implications of these scenarios, such as the net environmental flows in significant river systems and the net oil import volumes required, are shown in Figs. 5 and 6 . It is important to note that these results are from 'unresolved' scenarios, i.e. no effort has been made to alleviate the tensions that appear in these scenario conditions. So in Fig. 5, the settings lead to 'negative' flows in rivers because more water is being extracted than is available from the catchment. The different settings in the scenarios seethis occur in different time frames, with the least damaging result in the DIY scenario, due to the reduction in irrigated cropland of $75 \%$ by 2035.

In all scenarios except DIY, environmental flows in rivers reached zero or below zero levels by 2060 . In terms of net oil imports, demand increased in the short term in all scenarios except in the case of DIY when very significant changes to the mode of passenger and freight transport were implemented.

\section{Suitability of this method for food system analysis}

Through this project, we tested an exploratory process for unpacking food system complexity. The process responds to some of the inherent difficulties in food systems analysis, by enabling us to:

\& Explore systemic leverage points: Ingram (2011) argue that focusing on the outcomes of food system behaviour (e.g. yield or calorific intake) offers little value for identifying how and where to influence food systems. Instead, they suggest a focus on the drivers and dynamics underlying food system behaviour as a way to identify points of leverage.

\& Explore non-linear relationships, in contrast to more traditional economic explorations that tend to assume linear relationships between causal factors and rely on data set correlations to imply lessons for environmental or policy changes (Giraldo et al. 2008). This approach inevitably 
Table 1 Quantitative settings used in the Victorian Food Supply Scenarios Project

\begin{tabular}{|c|c|c|c|}
\hline & Adjustment & Time to take control & $\begin{array}{l}\text { DIY } \\
\text { (communities, towns and regions) }\end{array}$ \\
\hline \multirow{2}{*}{$\begin{array}{l}\text { Greenhouse emissions } \\
\text { (target values-reduction on } 1990 \text { levels) }\end{array}$} & 15-20 \% by 2030 & $60 \%$ by 2030 & $60 \%$ by 2030 \\
\hline & $45 \%$ by 2060 & $80 \%$ by 2060 & $90 \%$ by 2060 \\
\hline \multicolumn{4}{|l|}{ Land and water use } \\
\hline \multirow{2}{*}{$\begin{array}{l}\text { Reduction in productive (food) } \\
\text { land by } 2035\end{array}$} & $-20 \%$ & $-20 \%$ & $-15 \%$ \\
\hline & To forests for bioenergy & $\begin{array}{l}\text { To forests for bioenergy and } \\
\text { sequestration }\end{array}$ & $\begin{array}{l}\text { To forests for sequestration } \\
\text { only }\end{array}$ \\
\hline $\begin{array}{l}\text { Urban land use (all changes in urban } \\
\text { land use are exchanged with land } \\
\text { use of 'grazing') }\end{array}$ & $\begin{array}{l}\text { Follow trend of increasing } \\
\text { population at current rates } \\
\text { for household formation, } \\
\text { density, etc. }\end{array}$ & $\begin{array}{l}\text { Stop conversion of productive } \\
\text { land to residential, } \\
\text { increasing high-rise density }\end{array}$ & $\begin{array}{l}\text { Contracting urban area, more } \\
\text { people per dwelling, larger } \\
\text { households, renovation/ } \\
\text { adaptation }\end{array}$ \\
\hline $\begin{array}{l}\text { Reduction in proportion of cropland } \\
\text { irrigated by } 2035\end{array}$ & $40 \%$ & $60 \%$ & \\
\hline \multicolumn{4}{|l|}{ Energy } \\
\hline Energy efficiency (across economy) & $40 \%$ & $40 \%$ & \\
\hline Energy production & $\begin{array}{l}30 \% \text { renewable by } 2030, \\
\text { increased gas, carbon capture } \\
\text { and storage from } 2025\end{array}$ & Conversion to gas & sion to renewable \\
\hline \multicolumn{4}{|l|}{ Transport } \\
\hline Efficiency/demand reduction & Fuel efficiency & Fuel efficiency & $\begin{array}{l}\text { Fuel efficiency, demand and } \\
\text { distance reduction }\end{array}$ \\
\hline Mode change & & $90 \%$ freight on rai & $50 \%$ freight on rail \\
\hline $\begin{array}{l}\text { Fuel substitution (where not stated, } \\
\text { changes are applied out to 2035) }\end{array}$ & $\begin{array}{l}15 \% \text { electric vehicles for new } \\
\text { passenger vehicles from } 2011 \\
10 \% \text { to compressed gas } \\
1 \% \text { p.a. increase in crop } \\
\text { diversion to biofuel }\end{array}$ & $\begin{array}{l}100 \% \text { electric for new passenger } \\
\text { vehicles from } 2011 \\
\text { Switch to gas for remaining road } \\
\text { freight }\end{array}$ & $\begin{array}{l}10 \% \text { p.a. increase in crop } \\
\text { diversion for biofuel }\end{array}$ \\
\hline \multicolumn{4}{|l|}{ Agricultural production } \\
\hline Energy efficiency & $40 \%$ as per overall & $40 \%$ as per overall & $50 \%$ as per overall \\
\hline \multicolumn{4}{|l|}{ Water efficiency (\% change pa): } \\
\hline Intensity of application (reduces) & $0.5 \%$ & $0.5 \%$ & $1 \%$ \\
\hline Yield (increases) & $0.5 \%$ & $0 \%$ & $0 \%$ \\
\hline \multicolumn{4}{|l|}{ Fertiliser efficiency ( $\%$ change pa): } \\
\hline Intensity of application (reduces) & $0.2 \%$ & $1 \%$ & $0.5 \%$ \\
\hline Yield (increases) & $1 \%$ & $1 \%$ & $0.5 \%$ \\
\hline Labour productivity & As per background & As per background & $-2 \%$ per annum, agriculture only \\
\hline \multicolumn{4}{|l|}{ Net food availability } \\
\hline Food required (waste and losses) & $50 \%$ of food produced is wasted/lost & $44 \%$ of food is wasted/lost & $33 \%$ of food is wasted/lost \\
\hline Food available & Any deficits met through imports & $\begin{array}{l}\text { Reallocate resources to produce } \\
\text { nutritious diet in Australia }\end{array}$ & $\begin{array}{l}\text { Reallocate resource to produce } \\
\text { nutritious diet in Victoria }\end{array}$ \\
\hline
\end{tabular}

misses many of the relationships (including non-linear dynamics) that exist between factors affecting food security?

\& Overcome the lack of large-scale (national-global) scenarios designed to investigate the many issues that underpin food security. Previous reviews of food security-related scenarios found only production, and availability issues were covered comprehensively (Zurek 2006).

The Victorian Food Supply Scenarios Project has now been extended into a multi-year national project funded by the
Australian Research Council, which deepens and extends the analysis in five ways:

\& Extending from Victoria only to Australia wide;

\& Exploring multiple different dietary profiles as ways of meeting nutritious dietary requirements;

\& Deepening understanding and analysis of agricultural production systems, including the emergence of sustainable/regenerative techniques;

\& Testing new methodologies for combining physical and economic analysis of the food system, including costs/benefits of different approaches; and 


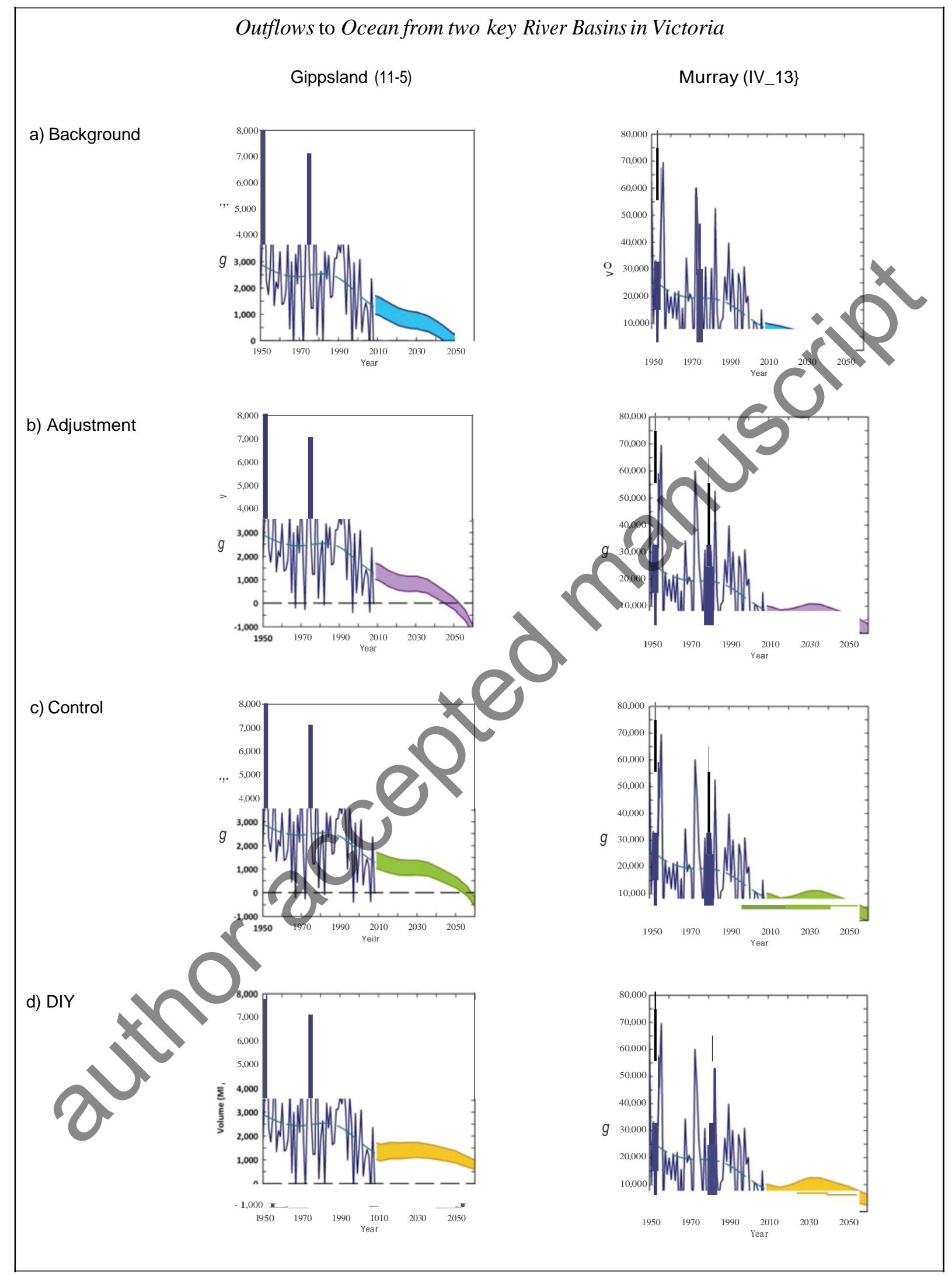

Fig. 5 Net environmental flows. a Background. b Adjustment. c Control. d DIY 


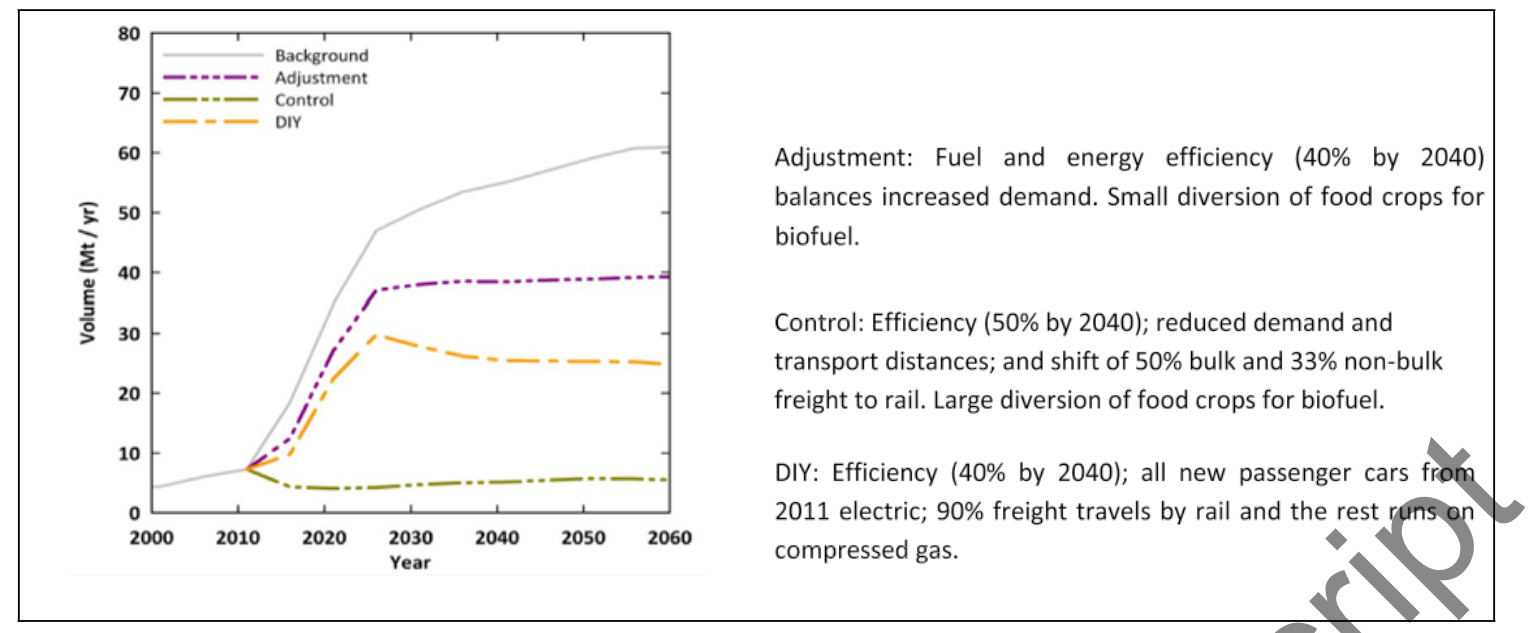

Fig. 6 Net oil import volume (all) (crude and refined)

\& Exploring if/how this approach can be extended to explore food system resilience and vulnerability.

\section{Food system vulnerability and resilience}

In this section, we explain how the process developed for exploring future production scenarios will be extended to explore resilience in the Australian food system, for the Australian Food Supply Scenarios Project. We explain the challenges with modelling and measuring resilience drawing on learning from other simulation models developed to assess risk and resilience in production systems. We then outline how the scenario modelling and ASFF analysis will be used to address these challenges.

Table 2 Net food availability (Victoria)

\begin{tabular}{|c|c|c|c|c|c|c|}
\hline & \multicolumn{2}{|c|}{ Adjustment (Vic) } & \multicolumn{2}{|c|}{ Control (Aus.) } & \multicolumn{2}{|c|}{ DIY (Vic) } \\
\hline & 2030 & 2060 & 2030 & 2060 & 2030 & 2060 \\
\hline \multicolumn{7}{|l|}{ Vegetables } \\
\hline \multicolumn{7}{|l|}{ Fruit } \\
\hline \multicolumn{7}{|l|}{ Milk } \\
\hline \multicolumn{7}{|l|}{ Meat } \\
\hline \multicolumn{7}{|l|}{- Beef } \\
\hline \multicolumn{7}{|l|}{ - Lamb } \\
\hline \multicolumn{7}{|l|}{ - Nuts } \\
\hline \multicolumn{7}{|l|}{ Cereal grains } \\
\hline \multicolumn{7}{|l|}{ - Food and feed } \\
\hline - Including fuel & & & $\mathrm{a}$ & $\mathrm{a}$ & & \\
\hline \multicolumn{7}{|l|}{ Oil } \\
\hline \multicolumn{7}{|c|}{ - Food and feed } \\
\hline - Including fuel & & & $\mathrm{a}$ & a & & \\
\hline \multicolumn{7}{|l|}{ Sugarb } \\
\hline \multicolumn{7}{|l|}{ - Food and feed } \\
\hline - Including fuel & & & $\mathrm{a}$ & $\mathrm{a}$ & & \\
\hline
\end{tabular}

\begin{tabular}{|l|c|c|c|c|c|c|}
\hline Key & Large surplus & Small surplus & Borderline & Small deficit & Large Deficit & N.A. \\
\hline
\end{tabular}

NB. These are indicative categories, determined by reading off the net food graphs. The ratings refer to the relative size of the surplus or deficit to other foods within that scenario and context. They do not take into account the proportion of total requirement this reflects, or the relative surplus or deficit to the same food category in the other scenarios

${ }^{a}$ Minimal use of biofuel in control

${ }^{\text {b } V i c t o r i a ' s ~ n e g l i g i b l e ~ s u g a r ~ p r o d u c t i o n ~ i s ~ n o t ~ e x p e c t e d ~ t o ~ c h a n g e, ~ s o ~ i s ~ a ~ s t a t e-l e v e l ~ d e f i c i t ~ i n ~ a l l ~ s c e n a r i o s ~}$ 
Complexity and resilience

As the complexity of food systems have grown, so too have the risks and vulnerabilities. In the last decade, events such as floods and drought, financial market volatility and energy price increases have demonstrated how easily shocks can cascade throughout the global food system (Lagi et al. 2011b; Liverman and Kapadia 2010; Spratt 2013). The close integration between our critical infrastructures of provision has 'primed' modern economies for systemic risk. Major disruptions can have multiple causes that are often unpredictable, affect separate corners of the globe and often involve cascading dynamics that cannot be contained (Little 2002; WEF 2014). Governments, business and infrastructure managers recognising this risk landscape are turning to the concept of resilience as a new 'frame' for risk mitigation.

Compared to traditional risk management frames, resilience offers a more nuanced and 'systems literate' perspective on the vulnerabilities and hazards facing the global food system. However, resilience is poorly translated into practice. One of the main hurdles to applying resilience is simply defining what it means in a way that can be assessed and measured.

Two main and contested definitions of resilience frame it as either a stability-seeking rebound property, where a system returns to a state prior to shock (Gunderson 2000), or as an adaptive property, where a system changes in the face of multiple stressors to maintain coherence (Reid and Botterill 2013). The former, 'engineering' frame has the advantage of being simpler to quantify. For example, as time taken for a system to fail after being subjected to a shock or for a system to recover a pre-shock position or level of function (Henry and Ramirezmarquez 2012). This works well for specific assets or functions (like a processing facility) and considering short-term shocks. But it is a blunt instrument when managing a complex multi-layered food system. Speed of recovery is a retrospective value that tells little about the suitability of the system or function in focus, the frequency on causes of failure, resources required to recover or even whether the original 'level of function' is desirable. Just because a system recovered rapidly from a particular shock indicates little of its ability to recover from the next one.

The conception of resilience as an adaptive process better reflects the evolying complexity of food systems but is difficult to quantify. Arguably, this resilience-as-adaptation framing gives a clearer articulation of the dynamics affecting resilience at a whole food system level because it emphasises the role of cross-scale factors in exacerbating hazards and enabling flexibility. For example, it highlights the inevitability of trade-offs between system efficiency and flexibility and between a system's resilience to different types of threats (building resilience to one shock can reduce it to others). Additionally, this framing treats resilience as a state in flux-shaped by multiple slow- and fast-moving variables operating at different scales (Apeldoorn et al. 2011). Compared to static conceptions of resilience, this perspective better encapsulates how extreme weather events or supply chain delivery times (fast-moving variables) are part of the same risk landscape as slow-moving variables like population growth or soil erosion rates. To understand how resilience can be built across the food system, diverse shocks and stressors must be explored together.

While this framing has an explanatory value, it does not easily translate to decision-making. Rather than resilience being an outcome, it depends on fuzzy attributes-such as modularity, redundancy and tight feedbacks (OIsson et al. 2006) that are difficult to quantify and compare. Knowing that functional redundancy is critical tells us nothing about the tradeoffs between different types of redundancy, or how to quantify the benefits of building in additional redundancy to a system.

Currently, resilience research has failed to bring simple quantifiable metrics together with a more nuanced understanding of the dynamics that underpin vulnerability and adaptation. This presents a key challenge for those interested in food system resilience. Policymakers and supply chain managers in the food system need to know how to read the complex background dynamics affecting food system resilience on multiple time scales. But they also need simple 'red-flag' indicators showing where food systems are approaching failure thresholds or when resources needed for adaptation are critically low.

\section{Limitations to traditional and emerging 'risk/impact' modelling approaches}

Infrastructure simulation and modelling represent an area of research where organisations are grappling with how to quantify and measure risk, vulnerability and resilience in complex provision systems. Governments and research agencies have stepped up efforts to develop risk simulation models for infrastructure systems since events such as hurricane Katrina exposed the fragility of critical service systems (Steinberg et al. 2011; Yusta et al. 2011). Much of this work is focused on impacts and threats to financial, logistics, energy and ITC systems (Giannopoulos et al. 2012) and do not consider food. However, since food systems rely on these infrastructures, they offer a useful point of reference for understanding the challenges and trade-offs when exploring risk and resilience using ASFF. The following points highlight common deficiencies:

1. A narrow focus on impact assessment. Many models which claim to assess resilience or vulnerability of infrastructure systems are actually impact simulators. These types of models tend to be designed for asset or network managers who have clearly defined responsibilities at a 
sub-system level and are often sophisticated as decisionmaking aids that relate directly to real-life management issues. However, they tend to take a narrow focus in infrastructure systems (e.g. at the facility level). For example, they cannot explore up or downstream risks and do not take into account interactions between sectors (Giannopoulos et al. 2012; Leclaire et al. 2012). The development of infrastructure simulations based on impact and risk assessment methods explains many of the other model limitations listed below.

2. An inability to consider multiple types of shocks and stressors simultaneously. Models geared to assessing critical system vulnerabilities typically simulate shortduration shocks such as natural disasters, supply chain disruptions or component failures. These 'stressors' have immediate and quantifiable impacts on functions or assets. Models are less capable of exploring impacts from slow-moving 'stressors'. This is a major downside because it is often the gradual 'chronic' stressors which are harder to detect, more difficult to evaluate and responsible for pushing complex systems close to failure thresholds (Leclaire et al. 2012).

3. High levels of abstraction. Many of the models built to explore resilience or highly complicated aspects of infrastructure failure (such as cascading shocks) are highly abstract (Chai et al. 2011; Chang et al. 2014). These models are often generated for research purposes to explore theoretical questions rather than real-world scenartos (Falasca et al. 2008). Results often have little direct value for decision-makers.

4. An inability to capture emergent system behaviour. Many models are focused on system responses to external threats and/or the outcomes of a shock and do not consider internal dynamics that can heighten risk. Typically, models (such as the USA-based CIPDSS) that can explore emergent behaviour (often agent-based simulations) only explore dynamics over shorf-time frames of days to weeks (Steinberg et al. 2011)

5. An inability to explore adaptive system properties. Many models do not explore adaptation as a response to disturbance and therefore ignore the capacity of systems to repair, re-route or use other means to maintain function (Filippini and Silva 2012). While there are exceptions, (such as the Australian CIPMA model), they rarely consider the accumulative costs of adaptation such as the erosion of resources. These dynamics are critical for understanding capacity for future recovery.

6. A focus on measuring outcomes over understanding dynamics. Understandably, many models are primarily concerned with the consequences of shocks on system performance criteria-such as on yields or production rates. A focus on outcomes often means internal system dynamics are treated like a 'black box'. These models offer no way to explore how shocks affect infrastructure systems and where thresholds might exist. Furthermore, output levels (such as volumes or price) are a poor indicator of system stability, do not indicate if vulnerabilities exist and do not show the existence of trade-offs between shortterm outcomes and long-term system resilience.

It is important to note that the issues described often reflect deliberate compromises and differing priorities among model designers and users. However, they show how (in general) the current modelling 'state of the art' struggles to reflect the full range of complex dynamics responsible for resilience among multiple interconnected infrastructure systems. These issues reflect challenges to be overcome if we are to understand the key dynamics shaping food system resilience. Food system simulation is still in an exploratory phase.

Despite the large body of research on threats to food systems and on the impacts from food system failure, there is surprisingly little research on the dynamics or indicators of food system health aside from coarse performance criteria such as production yields, price or nutrient intake. Researchers are still at the stage of identifying the significance of relationships and functions. Before we can identify strategies to mitigate shocks, we need to understand more about how the system behaves under stress. This challenge is ideally suited to modelling and simulation.

Factors and dynamics of food system vulnerability

and resilience

One of the major hurdles to understanding what affects food system resilience is lack of knowledge about the simultaneous and cumulative effects of multiple shocks and stressors. In theory, by looking at multiple disturbances in the food system over different time and spatial scales, we can identify which conditions may be generic or specific indicators of vulnerability. Ideally, we can also determine which relationships are more or less important in underpinning the food system's ability to maintain functions. This understanding can provide a starting point for 'tweaking' resilience in desired ways.

Exploring fast-moving shocks and gradual stressors together is arguably more complex in food systems than other infrastructures of provision such as energy or water systems. Food systems encompass a diversity of spatial scales relying on environmental dynamics at the planetary scale and economic factors at the household level. Tracking impacts is also highly complex because failure in any domain of the food system (production, processing and packaging, distribution and retailing and consumption) can have major knock-on consequences for society more broadly. Key functions in each of these domains also depend on infrastructure systems at every stage from production to consumption-each with their own 
vulnerabilities. Because of this diversity, the global food system is vulnerable to forces operating at vastly different time scales-from centuries (e.g. land degradation) to days (e.g. just-in-time supply chain disruptions). Adding to this complexity, the food system is also changing in ways that add new risks. For example, the rise of bio-energy in the last two decades means food production and the energy sector are now tightly linked (Lagi et al. 2011a). The rise of food trading for short-term capital investment (rather than for consumption) has also introduced novel price dynamics that did not exist a decade ago (vonBraun and Tadesse 2012).

To demonstrate some of the complexities and relationships that require exploration, we outline a range of functions and conditions key to food system performance in Table 3. These factors were identified through analysis of literature and are 'developed world' in focus. They represent vulnerabilities at all scales in the Australian food system and were chosen to explore how shocks might propagate across the different food system domains. We also highlight a range of hazards divided into fast-moving acute 'shocks' and slow- moving chronic stressors with possible indicators of change. Bearing in mind the problems with using performance indicators as surrogates for system resilience or vulnerability, these indicators offer starting points for exploring sensitivity to impacts and for understanding relationships between indicators of food system health.

\section{ASFF for modelling food system resilience}

The project will use ASFF to explore the implications of contrasting "disruption scenarios" on the Australian food system. This exploration wilk not only track impacts but also seek to identify critical relationships at the heart of impact propagation and also the state of key variables (stocks and flow rates) that are correlated to the amplification or buffering of shocks. These indicators will then be used to explore how different food system configurations may affect the maintenance of desired functions under stress conditions.

Table 3 Indicators of stress/vulnerability in food systems

\begin{tabular}{|c|c|c|c|c|c|}
\hline $\begin{array}{l}\text { Food system } \\
\text { domain }\end{array}$ & $\begin{array}{l}\text { Critical inputs to sector } \\
\text { (sensitive to disruption) }\end{array}$ & Fast-moving shocks & $\begin{array}{l}\text { Potential indicator/ } \\
\text { symptom }\end{array}$ & $\begin{array}{l}\text { Slow-moving } \\
\text { stressors }\end{array}$ & Potential indicator/symptom \\
\hline \multirow[t]{3}{*}{ Production } & $\begin{array}{l}\text { Physical/biological: } \\
\text { landscape functions (fertility, } \\
\text { area, etc.), climate } \\
\text { (rainfall, temperature) }\end{array}$ & ne weatl & & $\begin{array}{l}\text { Soil salinity } \\
\text { Climate shift }\end{array}$ & $\begin{array}{l}\text { ha under cultivation/yield/ha } \\
\text { Input costs/yield }\end{array}$ \\
\hline & $\begin{array}{l}\text { Highly mechanised and } \\
\text { dependent on fossil-fuel } \\
\text { based inputs such as } \\
\text { fertilisers, pesticides and } \\
\text { herbicides and is } \\
\text { subsequently impacted by } \\
\text { oil availability and price } \\
\text { fluctuations }\end{array}$ & Disruptions to & & $\begin{array}{l}\text { Decline in water avail. } \\
\text { Poor land management } \\
\text { Energy and fertiliser costs } \\
\text { Urban sprawl } \\
\text { Oil scarcity } \\
\text { Nutritional surplus/deficit } \\
\quad \text { to population needs }\end{array}$ & $\begin{array}{l}\text { Decline rate in farm terms } \\
\text { of trade } \\
\text { Soil fertility decline rate } \\
\text { \$/barrel } \\
\text { Local production as \% of } \\
\quad \text { total population } \\
\text { nutritional requirement }\end{array}$ \\
\hline & $\begin{array}{l}\text { Economic: } \\
\text { labour market factors; } \\
\text { commodity prices and } \\
\text { global/local trade } \\
\text { relationships }\end{array}$ & Dlatility & Interest rates & $\begin{array}{l}\text { Productivity investment } \\
\text { Aging population }\end{array}$ & $\begin{array}{l}\% \text { contribution to Ag R\&D } \\
\text { as proportion of Ag. GDP } \\
\text { \$/ha/year } \\
\text { Decline rate in } \% \text { of } \\
\quad \text { pop }>18<55\end{array}$ \\
\hline $\begin{array}{l}\text { Processing } \\
\text { and } \\
\text { packaging }\end{array}$ & $\begin{array}{l}\text { Availability of labour and } \\
\text { energy for machinery } \\
\text { Availability of inputs for } \\
\text { plastic packaging-mainly } \\
\text { oil although some vegetable } \\
\text { substitutes are available. }\end{array}$ & $\begin{array}{l}\text { Wage costs } \\
\text { Disruptions to farm inputs } \\
\text { Energy price volatility }\end{array}$ & $\begin{array}{l}\text { Input costs/yield } \\
\text { Production rates }\end{array}$ & $\begin{array}{l}\text { Aging population } \\
\text { Productivity investment } \\
\text { Oil scarcity }\end{array}$ & $\begin{array}{l}\text { Decline rate in } \% \text { of } \\
\text { pop }>18<55 \% \\
\text { contribution to processing } \\
\text { R\&D as proportion of } \\
\text { processing GDP } \\
\text { \$/barrel }\end{array}$ \\
\hline $\begin{array}{l}\text { Distribution } \\
\text { and retail }\end{array}$ & $\begin{array}{l}\text { Energy availability for } \\
\text { refrigeration } \\
\text { Energy (usually oil) for } \\
\text { transport, electricity also } \\
\text { for rail distribution }\end{array}$ & $\begin{array}{l}\text { Extreme weather } \\
\text { Energy price volatility }\end{array}$ & $\begin{array}{l}\text { Volume delivery rates } \\
\text { Inventory stock levels } \\
\text { Days lost production/year } \\
\text { Input costs/volume } \\
\text { delivered }\end{array}$ & $\begin{array}{l}\text { Oil scarcity } \\
\text { Productivity investment }\end{array}$ & $\begin{array}{l}\text { \$/barrel } \\
\% \text { contribution to processing } \\
\text { R\&D as proportion of } \\
\text { processing GDP }\end{array}$ \\
\hline Consumption & $\begin{array}{l}\text { Energy for refrigeration, } \\
\text { preparation and transport } \\
\text { Household income }\end{array}$ & $\begin{array}{l}\text { Extreme weather Energy } \\
\text { disruption Loss of } \\
\text { household income }\end{array}$ & $\begin{array}{l}\text { Average } \% \text { food costs of } \\
\text { income }\end{array}$ & $\begin{array}{l}\text { Shifts in food choice } \\
\text { Rising energy cost }\end{array}$ & $\begin{array}{l}\text { Average nutritional intake } \\
\text { Average } \% \text { food costs of } \\
\text { income } \\
\% \text { energy costs of household } \\
\text { income }\end{array}$ \\
\hline $\begin{array}{l}\text { Trade/markets/ } \\
\text { pricing }\end{array}$ & Market regulation & $\begin{array}{l}\text { Trade volatility } \\
\text { Global economic } \\
\text { stability } \\
\text { Social unrest }\end{array}$ & $\begin{array}{l}\text { Exchange rate } \\
\% \text { of trade for investment } \\
\text { reasons } \\
\% \text { of domestic production } \\
\text { retained for domestic } \\
\text { market }\end{array}$ & $\begin{array}{l}\text { National Ag terms of trade } \\
\text { Bio-fuel subsidies }\end{array}$ & $\begin{array}{l}\% \text { of food crop diverted for } \\
\text { energy production }\end{array}$ \\
\hline
\end{tabular}


Strengths and limitations of ASFF for modelling food system resilience

ASFF has a number of strengths making it suitable for exploring the dynamics and relationships that define resilience in food systems.

Capacity to open up the model 'black box'

ASFF was created and is applied to problems according to the 'Design Approach' (see Gault et al. 1987). In the latter application phase, quantitative scenarios are designed and created in ASFF by the user (operating in 'decision space') and then re-designed until physically realistic (in the 'machine space' occupied by the ASFF), and desirable outcomes are created. This process relies on the transparent nature of the ASFF, where feedbacks based on human reactions (e.g. social, economic, technological) are implemented through integration with other models or managed directly by the user. So, responses to the tensions in the physical situation depicted in the ASFF are explicit and conscious. In this way, ASFF is more like a flight simulator than a 'black box' model.

This allows analysts to extract and view the impact of shocks and stressors on multiple sub-functions within the food system simultaneously. This ability to 'open up' the simulation at various points across the food system is ideal for identifying relationships between critical variables; for example, between upstream functions and final outputs (e.g. yield). Where outputs alone represent a blunt measure of system resilience, understanding the correlations and relative levels of influence between stocks and flow rates can help identify upstream predictors that may act as 'red flags' that downstream functions will be affected.

Capacity to explore both slow- and fast-moving disruptions

Where many models are concerned only with temporary shocks and their short-term dynamics, ASFF can simulate multiple shocks over different time scales, for example incorporating shocks occurring over days (e.g. supply chain disruptions), months (e.g. commodity-price hikes) and decades (e.g. workforce availability). This capacity is particularly important for understanding food system resilience since key functions are vulnerable to many slow-moving variables that are difficult to detect and often ignored. Exploring slow and fast stressors simultaneously can help show which stressors have synergies and amplify each other.

\section{Incorporates multiple interconnected sectors}

Because ASFF is concerned only with physical stocks and flows across the economy, it can seamlessly integrate functions delivered by multiple sectors and infrastructure systems.
This means ASFF avoids problems that arise in other multisector simulators where models designed specifically for different sectors are forced to interact. However, the focus on physical stocks and flows means there are limits in how non-physical 'shocks' such as price volatility can be modelled. For example, in this case, price changes would need to be translated into an assumed change in physical stocks-such as import and export rates.

\section{Limited capacity to model feedback dynamics}

In its current design, the model does not incorporate many of the feedback processes that could be used to explore dynamics of recovery or emergent change. For example, it cannot simulate the re-direction of resources from one sector of the economy to another in response to animpact or threat of impact nor can it currently simulate the emergence of behavioural adaptations. Some recovery processes such as land regeneration can be explored, but these are defined by pre-determined rates.

Implications

ASFF is ideally suited to exploring the impacts of diverse shocks and stressors but is constrained in the ways it can reflect and explore resilience. Its greatest strength is being able to explore and compare multiple sub-systems simultaneously over different time scales. The ability to correlate overall system outputs (e.g. in terms of yield) with subsystem health (e.g. workforce retention rates) also allows the analyst to explore where trade-offs between sub-system functions exist. This may be used to understand how deliberate changes to improve resilience in one part of the food system may undermine it in others. Its capacity to explore how impacts cascade can also help prioritise where resilience building efforts should be directed.

As ASFF cannot currently simulate recovery or adaptive processes easily, resilience must be explored using a resistance or rebound framing of resilience. Given the capacity of ASFF to explore impacts over time, suitable metrics for resilience could include time to failure or failure frequency. By themselves, these factors are fairly blunt and of limited value except where comparing the performance of different food system configurations under stress conditions. However, because ASFF enables the analyst to visually assess multiple stocks and flow processes at different scales simultaneously, these blunt metrics can be used as valuable points of reference. For example, they can be used as the basis for exploring influential 'upstream' system characteristics such as critical 'key-stone' stocks or stock threshold levels. These, in turn, can help identify critical relationships at smaller scales across the food system. By identifying and differentiating the importance of stocks and flows under different stress conditions, this 
information can help guide efforts to build food system resilience.

Approach—how will we use ASFF?

The Australian Food Supply Scenarios Project will use ASFF to explore food system resilience by exploiting the model's capacity to simulate slow- and fast-moving shocks at multiple scales and explicitly link downstream outputs to upstream stocks and flow conditions.

Similar to the method described above, exploration of vulnerability and resilience will employ exploratory scenarios designed to incorporate multiple pressure conditions comprising gradual 'chronic' stressors and fast 'acute' shocks (as in Table 3). Four scenarios will be created. The first scenario will run during the period between 2010 and 2025. This scenario reflects the real inertia in the system by exploring the effects of current trends and policies on the trajectories of key stocks and creates a snapshot of the system as it might look like in 2025. This snapshot of the key stocks in the food system will expose the development of chronic stressors during the period and allow evaluation of the resilience of the 2025 system to acute shocks. To allow the exploration of what can be done to relieve stressors and improve resilience, the other scenarios will represent three potential response pathways from 2025 forward. Each will capture differentfood system design possibilities including combinations of the production measures and potential environmental implications indicated in Tables 4 and 5. The implications of each food system configuration on functional health and capacity to deliver desired yield levels will be explored.

Our analysis of the final scenarios will include the following:

\& Effective combinations of food system design features (such as the different agricultural methods shown in Table 5) to ameliorate the stressors in the food system; and

\& The impact of shocks (such as oil supply disruptions, weather events, etc.) on the relative resilience of the difference scenarios.

\section{Proposed method}

The project will use a four-stage process to explore and identify critical factors in Australia's food system. A summary of this process is described as follows:

1. Develop a set of key stock levels (including yield, yield rates and land factor decline rates) that will act as surrogates for system (or sub-system) failure. For this

Table 4 Example components and indicators from the scenarios used in Australian Food Supply Scenarios Project

\begin{tabular}{|c|c|}
\hline $\begin{array}{l}\text { Scenario (key components) } \\
\text { Adjustment }\end{array}$ & \\
\hline \multicolumn{2}{|l|}{ Free markets, high levels of global trade } \\
\hline Resources allocated to those who & $\begin{array}{l}\text { Production (yield) as \% of population requirements for core food groups: as } \\
\text { high reliance on imported food (so lower domestic production \%) }\end{array}$ \\
\hline High import & $\begin{array}{l}\text { Decline of landscape function: soil quality and capability as affected by inter } \\
\text { monoculture agriculture }\end{array}$ \\
\hline & $\begin{array}{l}\text { Infrastructure decline rates: assume high decline rates due to market focus o } \\
\text { investment returns }\end{array}$ \\
\hline \multicolumn{2}{|l|}{ Time to take control } \\
\hline Resources allocated to meet core energy and food needs & $\begin{array}{l}\text { Yield/ha: could be higher due to high R\&D; lower with poor market signal } \\
\text { production innovation and farming systems. Expected focus on monocu } \\
\text { could increase disease susceptibility and extreme weather events. }\end{array}$ \\
\hline High investment in infrastructure and R\&D & $\begin{array}{l}\text { Infrastructure decline rates: assume better maintenance of regional and nati } \\
\text { infrastructure }\end{array}$ \\
\hline Strong planning protections & $\begin{array}{l}\text { Dependence on foreign oil (barrels imported): assuming a lower dependence } \\
\text { through investment in domestic alternatives }\end{array}$ \\
\hline \multicolumn{2}{|l|}{ Do it yourselves (DIY) } \\
\hline Light, mostly local govt. intervention & $\begin{array}{l}\text { Regional production (yield) as \% of population requirements for core food } \\
\text { groups: assumed low access to food imports }\end{array}$ \\
\hline Aim to meet core food requirements at local/regional level & $\begin{array}{l}\text { Infrastructure decline rates: assumed high rates of decline at regional and } \\
\text { national level }\end{array}$ \\
\hline Careful use of local resources & $\begin{array}{l}\text { Ratio of regional nutrient requirements to nutrient availability: assumed } \\
\text { limited ability to import nutrients }\end{array}$ \\
\hline
\end{tabular}




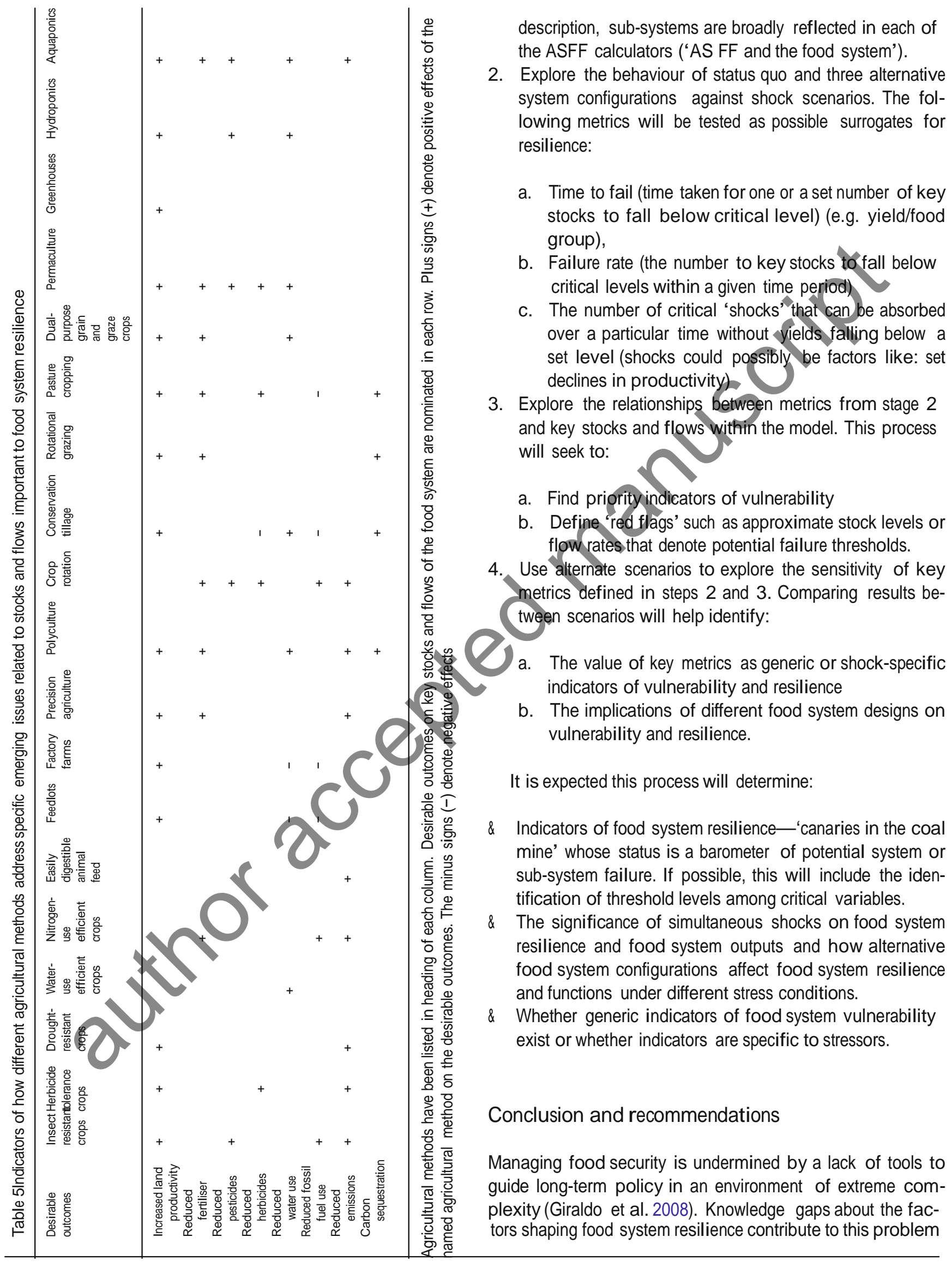


While there is a rich body of research on food security and what contributes to the failure of food systems, ultimately, the dynamic nature of food systems limits how much value can be derived from assessing possible risks and their impacts. The diversity of dynamic variables that shape impact propagation makes this type of linear impact assessment a guessing game at the whole-of-system level. In contrast, exploring food system behaviour under different stress conditions is more likely to reveal which variables are critical in building and undermining resilience and which variables are symptomatic of impending failure.

Scenario-based simulation modelling is an ideal way to explore these behaviours and identify which variables policy should consider and be based around. It is only through testing system behaviours under different conditions that we can gain a clear understanding of critical buffers and ideal buffer levels and about essential stocks and their threshold values. While not perfect, the ASFF model outlined in this paper is well placed for this type of exploration given its capacity to explore how diverse shocks and stressors affect food system behaviour across multiple sectors. Furthermore, its ability to simulate primary dynamics at the national level addresses a key 'scale' gap in food security research (Ericksen et al. 2009). The scenarios are not predictive, and they are not intended to dictate policy, but to shape it by increasing awareness and understanding of areas of vulnerability and high sensitivity-highlighting where attention should be paid, both in further research and in policy to reduce or ameliorate potential impacts.

While ASFF represents Australian agricultural and economic conditions, parts of its underlying structure are more generally applicable. As a minimum, adaptation to other contexts would require re-calibration and adjustment of geographic dimensions. Researchers considering developing a similar model or building on the work done in the current ASFF platform are suggested to contact the software developer Whatlf? Technologies and the corresponding author. The inability to directly apply ASFF to other national contexts does not undermine broader lessons; it can provide about what conditions can significantly influence food system resilience.

Improving the resilience of Australia's food systems is clearly vital to the country and many of its trading partners. However, it is worth recognising that building resilience in any system involves inevitable trade-offs that are often unseen. Ultimately, the choice of which threats are responded to, what form these responses take and how the resulting trade-offs in resilience are managed will be driven by political rather than scientific processes. This certainly appears the case in Australia, where the food system is often politicised. In these contexts, simulation modelling offers a way to make the consequences of policy decisions about building resilience and the resulting trade-offs more explicit. Whether this can help navigate the choices needed to ensure a 'food-bowl' versus 'dust-bowl' future remains to be seen.

Acknowledgments Candy and Larsen are researchers with an Australian Research Council Linkage Project, 'Modelling policy interventions to protect Australia's food security in the face of environmental sustainability challenges' (LP120100168), a collaboration between researchers at the Victorian Eco-Innovation Lab (VEIL) at the University of Melbourne, Deakin University and Australian National University. Aspects of this paper relating to resilience modelling were drawn from research funded by the Melbourne Sustainable Society Institute (MSSI) at the University of Melbourne.

\section{References}

Apeldoorn DFV, Kok K, Sonneveld MPW, Veldkamp T (2011) Panarchy rules: rethinking resilience of agroecosystems. Evidence from Dutch Dairy Farming. Ecol. Soc. 16

Australian Government (2014) Green paper on developing Northern Australia. Department of Premier and Cabinet, Canberra, Australia. Online: http://apo.org.au/sites/all/modules/pubdlcnt/ pubdlcnt. php?nid=40013\&file=http://northernaustralia.dpmc.gov. $\mathrm{au} /$ sites/default/files/papers/green_paper.pdf

Bartos S (2012) Resilience in the Australian food system. Australian Government, Department of Agriculture, Forests and Fisheries, Canberra, Australia. Online: http://www.tisn.gov.au/Documents/ Resilience\%20in\%20the\%20Australian\%20food\%20supply\% 20chain\%20-\%20PDF\%20copy\%20for\%20web.pdf

Baynes TM, Turner GM, West J (2010) Historical calibration of a water account system. J. Water Resour. Plan. Manag. 137:41-50

Chai CL, Liu X, Zhang WJ, Baber Z (2011) Application of social network theory to prioritizing oil \& gas industries protection in a networked critical infrastructure system. J. Loss Prev. Process Ind. 24:688-694. doi:10.1016/j.jp.2011.05.011

Chang SE, McDaniels T, Fox J, Dhariwal R, Longstaff H (2014) Toward disaster-resilient cities: characterizing resilience of infrastructure systems with expert judgments. Risk Anal. 34:416-434

Commonwealth Department of Health and Ageing (1998) Australian Guide to Healthy Eating. Commonwealth of Australia: Canberra. Online: http://www.healthpromotion.com.au/Documents/CIM/ fdcons.pdf

Dalal RC, Mayer RJ (1986) Long term trends in fertility of soils under continuous cultivation and cereal cropping in southern Queensland. I. Overall changes in soil properties and trends in winter cereal yields. Aust. J. Soil Res. 24:265-279

Dunlop M, Howden SM, Turner GM (2004) Future sustainability of the Australian grains industry. CSIRO Sustainable Ecosystems, Resource Futures Program

Erb KH, Haberl H, Krausmann F, Lauk C, Plutzar C, Steinberger JK, Muller C, Bondeau A, Waha K, Pollack G (2009) Eating the planet: feeding and fuelling the world sustainably, fairly and humanely-a scoping study. Commissioned by Compassion in World Farming and Friends of the Earth UK. (No. Working Paper No. 116). Institute of Social Ecology and PIK Potsdam, Vienna, Austria. Online: http://www.ciwf.org.uk/what_we_do/factory_farming/ eating_the_planet.aspx

Ericksen PJ (2008) What is the vulnerability of a food system to global environmental change? Ecol. Soc. 13(2):14

Ericksen PJ, Ingram JS, Liverman DM (2009) Food security and global environmental change: emerging challenges. Environ. Sci. Policy 12:373-377

Ericksen PJ, Stewart B, Dixon J, Barling D, Loring P, Anderson MD, Ingram J (2010) The value of a food system approach. In: Ingram J, 
Ericksen P, Liverman D (eds) Food Security and Global Environmental Change. Earthscan, London, United Kingdom

Falasca M, Zobel CW, Cook D (2008) A decision support framework to assess supply chain resilience, in: Proceedings of the 5th International ISCRAM Conference. pp. 596-605

FAO (2006) Food Security. Policy Brief Issue 2 (June 2006). Food and Agriculture Organisation of the United Nations, Rome

FAO (2011) The state of the world's land and water resources for food and agriculture: managing systems at risk. Food and Agricultural Organisation of the United Nations, Rome, Italy. Online: http:// www.fao.org/docrep/017/i1688e/i1688e.pdf

Farmar-Bowers Q, Higgins V, Millar J (eds) (2013) Food security in Australia. Springer US, Boston, MA

Filippini R, Silva A (2012) Resilience analysis of networked systems-ofsystems based on structural and dynamic interdependencies, in: PSAM 11 \& ESREL

Forrester J (1971) Counter-intuitive behaviour of social systems. Technology Review 73(3):52-68

Garnaut R (2008) The Garnaut Climate Change Review. Cambridge University Press, Port Melbourne, Final Report

Gault FD, Hamilton KE, Hoffman RB, Mclnnis BC (1987) The design approach to socio-economic modelling. Futures 19:3-25

Giannopoulos G, Filippini R, Schimmer M (2012) Risk assessment methodologies for Critical Infrastructure Protection. Part I A state of the art (No. 0039033278957). Ispra

Giraldo DP, Betancur MJ, Arango S (2008) Food security in development countries: a systemic perspective. Technology 1:1-15

Gunderson LH (2000) Ecological resilience-in theory and application. Annu. Rev. Ecol. Syst. 31:425-439

Hatfield-Dodds S, Turner G, Schandl H, Doss T (2008) Growing the green collar economy: skills and labour challenges in reducing our greenhouse emissions and national environmental footprint. Report to the Dusseldorp Skills Forum. CSIRO, Canberra, Australia. Online: http://dusseldorp.org.au/wp-content/uploads/2008/05/csiroreport.pdf

Henry D, Ramirez-marquez JE (2012) Generic metrics and quantitative approaches for system resilience as a function of time. Reliab. Eng. Syst. Saf. 99:114-122. doi:10.1016/j.ress.2011.09.002

Henzell T (2007) Australian agriculture: its historyand challenges. CSIRO Publishing, Collingwood, Australia

Ingram J (2011) A food systems approach to researching food security and its interactions with global environmental change. Food Secur. 3:417-431. doi:10.1007/s12571-011-0149-

Jones R, Turner G (2005) Economic analysis of identified impacts of climate change: a scoping study undertaken for the Australian Greenhouse Office by CSIRO and Collaborators. CSIRO, Canberra, Australia

Keating A (2013) Food security in Australia: the logistics of vulnerability. In: Farmar-Bowers Q, Higgins V, Millar J (eds) Food Security in Australia. Springer US, Boston, MA

Kenway S, Turner GM, Cook S, Baynes TM (2014) Water and energy futures for Melbourne: implications of land use, water use, and water supply strategy.J. Water Clim. Change 5(2):163-175

Lagi M, Bar-yam Yavni, Bertrand KZ, Bar-yam Yaneer (2011a) The food crises: a quantitative model of food prices including speculators and ethanol conversion. SSRN. Cambridge, MA. http://ssrn.com/ abstract=1932247 or http://dx.doi.org/10.2139/ssrn.1932247

Lagi M, Bertrand KZ, Bar-yam Yaneer (2011b) The food crises and political instability in North Africa and the Middle East. SSRN. Cambridge, MA. http://ssrn.com/abstract=1910031 or http://dx. doi.org/10.2139/ssrn.1910031

Larsen K, Turner GM, Ryan C, Lawrence M (2011) Victorian Food Supply Scenarios: impacts on availability of a nutritious diet. Victorian Eco-Innovation Lab (VEIL), University of Melbourne, Melbourne, Australia Online: http://www.ecoinnovationlab.com/
website/wp-content/attachments/Victorian-Food-Supply-ScenariosFull.pdf

Leclaire RJ, Pasqualini D, Dreicer JS, Toole GL, Urban NM, Bent RW, Mcpherson TN, Hengartner NW (2012) Infrastructure Modeling: Status and Applications. In: Linkov I (ed) Sustainable cities and military installations. Springer, Dordrecht

Little RG, (2002) Toward more robust infrastructure: observations on improving the resilience and reliability of critical systems, in: 36th Hawaii International Conference on System Sciences (HICSS'03)

Liverman D, Kapadia K (2010) Food systems and the global environment: an overview, in: Food Security and Global Environmental Change. Earthscan, London

Lowe D, Poldy F, Kearney B, Foran B, Turner GM (2003) Australian Fisheries Futures: 2020 and Beyond, CSIRO Resources Futures Working Paper Series 2003/2007. Canberra, Australia

NLWRA (2001) Australian agriculture assessment 2001. National Land and Water Resources Audit, Turner, A.C.T. Online: http://lwa.gov. au/files/products/national-land-and-water-resources-audit/ pr010238/pr010238.pdf

OECD-FAO (2008) OECD-FAO Agricultural Outlook 2008-2017. Organisation for Economic Co-operation and Development/Food and Agriculture Organisations of the United Nations

Olsson P, Gunderson LH, Carpenter SR, Ryan P, Lebel L, Folke C, Holling CS (2006) Shooting the rapids : navigating transitions to adaptive governance of social-ecological systems. Ecology and Society 11

PMSEIC (2010) Australia and food security in a changing world. The Prime Minister's Science, Engineering and Innovation Council, Canberra, Australia. Online: http://www.chiefscientist.gov.au/wpcontent/uploads/FoodSecurity_web.pdf

Poldy F, Conroy J (2000) Future Options to 2050: Australian stocks and flows framework. Report to the Department of Immigration and Multicultural Affairs; 00/04. CSIRO Sustainable EcoSystems (previously Wildlife and Ecology), Resources Futures Program, National Futures, Canberra, Australia

Reid R, Botterill LC (2013) The multiple meanings of Bresilience^: an overview of the literature. Aust. J. Public Adm. 72:31-40. doi:10. $1111 / 1467-8500.12009$

Reilly M, Willenbockel D (2010) Managing uncertainty: a review of food system scenario analysis and modelling. Philos. Trans. R. Soc. B Biol. Sci. 365:3049-3063. doi:10.1098/rstb.2010.0141

Singh RB (2000) Environmental consequences of agricultural development: a case study from the Green Revolution state of Haryana. India. Agric. Ecosyst. Environ. 82:97-103

Snoek M (2003) The Use and Methodology of Scenario Making. Eur. J. Teach. Educ. 26:9-19. doi:10.1080/0261976032000065607

Sobels J, Richardson S, Turner G, Maude A, Tan Y, Beer A, Wei Z (2010) Long term physical implications of net overseas migration: Australia in 2050. Department of Immigration and Citizenship, Australian Government, Canberra, Australia. Online: http://www.immi.gov. au/media/publications/research/_pdf/physical-implicationsmigration-fullreport.pdf

Spratt S, (2013) Food price volatility and financial speculation. Future Agricultures Working Paper 47. Online: http://www.ids.ac.uk/ downlo ad.cfm? o bj ectid =6D109C00-7B63-11E2 9DFF005056AA0D87

Steinberg LJ, Santella N, Zoli CB (2011) Baton Rouge Post-Katrina : the role of critical infrastructure modeling in promoting resilience. Homel. Secur. Aff. 7

Turner GM, Elliston B, Diesendorf M (2013) Impacts on the biophysical economy and environment of a transition to $100 \%$ renewable electricity in Australia. Energy Policy 54:288-299. doi:10.1016/j.enpol. 2012.11.038

Turner GM, Hoffman R, McInnis BC, Poldy F, Foran B (2011) A tool for strategic biophysical assessment of a national economy-the 


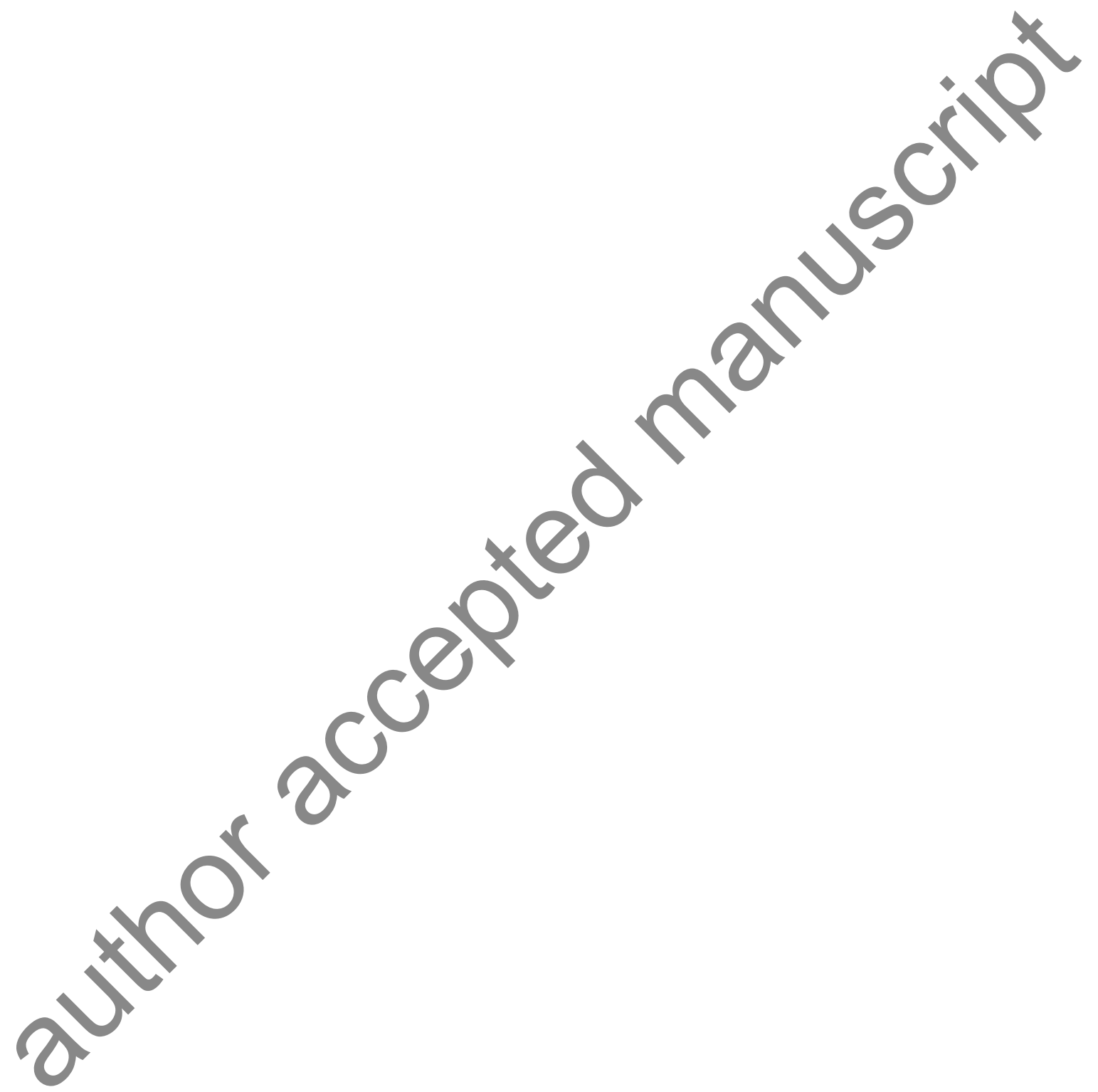


Australian stocks and flows framework. Environ. Model. Softw. 26: 1134-1149. doi:10.1016/j.envsoft.2011.03.007

VonBraun J, Tadesse G (2012) Global food price volatility and spikes: an overview of costs, causes, and solutions. ZEF - Discussion Papers on Development Policy No.161. Centre for Development Research, Bonn, Germany. Online: http://papers.ssrn.com/sol3/Delivery.cfm/SSRN_ ID1998164_code1480183.pdf?abstractid=1992470\&mirid=1

WEF (2014) Global Risks 2014 Ninth Edition. World Economic Forum. Geneva Online: http://www3.weforum.org/docs/WEF_ GlobalRisks_Report_2014.pdf
World Food Summit (1996) Declaration on World Food Security. Rome, Italy

Yusta JM, Correa GJ, Lacal-Arántegui R (2011) Methodologies and applications for critical infrastructure protection: Stateof-the-art. Energy Policy 39:6100-6119. doi:10.1016/j.enpol. 2011.07.010

Zurek MB (2006) A short review of global scenarios for food systems analysis. Wallingford, UK. Online: http://www. gecafs.org/publications/Publications/GECAFS_Working_ Paper_1_Zurek_March_2006.pdf 


\section{University Library}

\section{- M I N E R VA A gateway to Melbourne's research publications}

Minerva Access is the Institutional Repository of The University of Melbourne

\section{Author/s:}

CANDY, S;BIGGS, C;LARSEN, K;TURNER, G

Title:

Modelling food system resilience: a scenario-based simulation modelling approach to explore future shocks and adaptations in the Australian food system

\section{Date:}

2015

\section{Citation:}

CANDY, S., BIGGS, C., LARSEN, K. \& TURNER, G. (2015). Modelling food system resilience: a scenario-based simulation modelling approach to explore future shocks and adaptations in the Australian food system. Journal of Environmental Studies and Sciences, 5 (4), pp.712-731. https://doi.org/10.1007/s13412-015-0338-5.

Persistent Link:

http://hdl.handle.net/11343/122847 